\title{
ENSINO SOBRE SEGURANÇA DO PACIENTE: UMA REVISÃO INTEGRATIVA
}

\section{INTRODUÇÃO}

Atualmente, a inquietação em torno da segurança do paciente se mostrou como prioridade na área da saúde, pois, apesar do cuidado em saúde resultar em importantes benefícios a todos os envolvidos, os erros podem acontecer implicando em graves repercussões para os pacientes (RIGOBELLO et a., 2012). Os cursos da área da saúde têm uma função relevante para o aprendizado do estudante, principalmente no desenvolvimento de conceitos e habilidades sobre erros humanos e segurança do paciente, pois irão reproduzir na prática o que Ihes foi pontuado na teoria. (YOSHIKAWA et al., 2013). Destarte, diante da importância do tema apontado surgiu a pergunta norteadora dessa pesquisa: Qual é a produção cientifica em torno do ensino sobre segurança do paciente?

\section{Objetivo}

Conhecer a produção científica em torno do ensino sobre segurança do paciente nos últimos seis anos.
Jessica Guedes, Fabiane

Frigotto de Barros, Laysa

Fernanda Zerbinatti, Rubiane

Beal, Elaine Rossi Ribeiro

\section{RESULTADOS}

Dos artigos pesquisados apenas um é escrito na língua inglesa e o restante escrito em língua portuguesa, três são da área da enfermagem e um é da área da medicina, destes estudos dois foram publicados na Rev Gaúcha Enferm, um na Acta Paul Enferm e um na Acad Med. Quanto ao ano de publicação um artigo é de 2012, dois são de 2013 e um é de 2017. De maneira geral essas pesquisas se reportam à visão e compreensão dos estudantes sobre segurança do paciente, sendo que um deles ainda traz em voga a cultura de comportamentos inseguros.

Após leitura minuciosa de cada artigo, apresentase a categoria proveniente da análise e interpretação dos resultados que é :Compreensão dos estudantes sobre segurança do paciente

\section{MÉTODO}

Trata-se de revisão integrativa de literatura

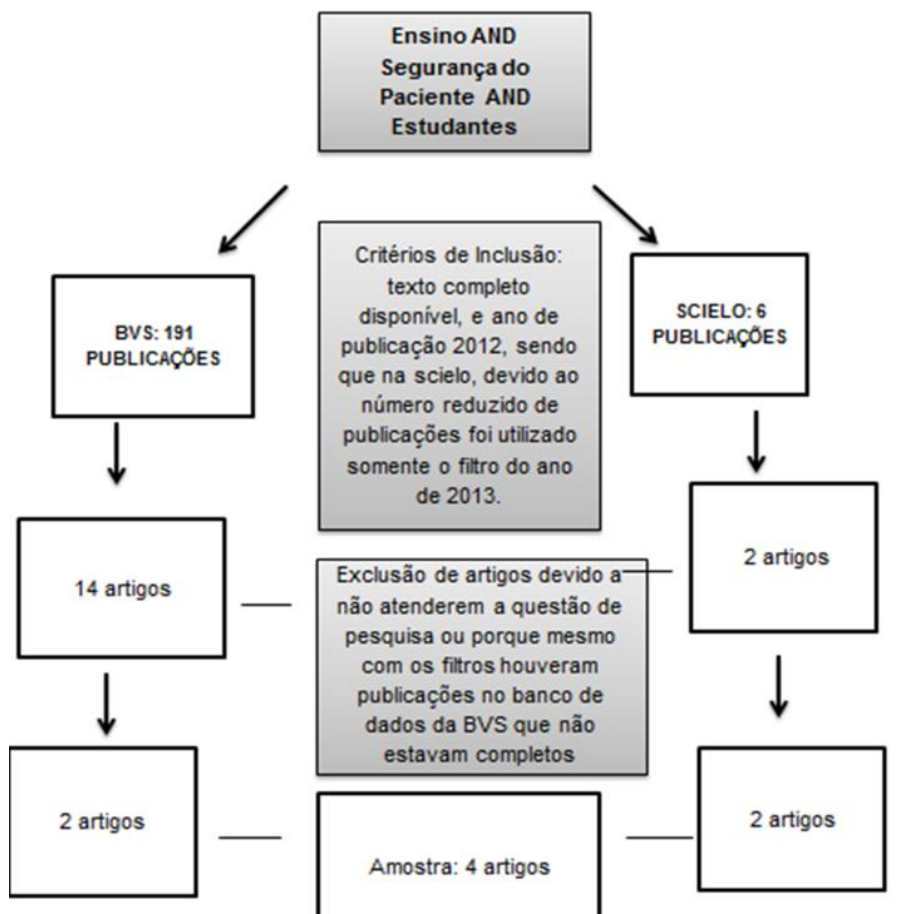

\section{CONCLUSÕES}

A inserção desse tema nas universidades é de suma importância, pois é o ensino e a formação que vão moldar os futuros profissionais, porém o que se observa é o fato de a segurança do paciente ainda ser um assunto que pouco estudado e publicado, pois como pode-se inferir na revisão, há apenas 4 publicações em seis anos. Visto a importância do tema, é fundamental que se pesquise mais sobre o assunto e que ele seja inserido nos currículos atuais da área da saúde, com o objetivo de qualificar a compreensão dos estudantes sobre o tema.

\section{REFERÊNCIAS}

1.YOSHIKAWA, J. M et al . Compreensão de alunos de cursos de graduação em enfermagem e medicina sobre segurança do paciente. Acta paul. enferm., São Paulo, v. 26, n. 1, p. 21 29, 2013. 